\title{
Revegetação das áreas mineiradas pela extração de ouro por draga nas margens do Rio Gualaxo do Norte, Mariana-MG.
}

\author{
Diogo Lyra de Toledo e Gazel ${ }^{1}$ \\ Diêgo Correa Ramos ${ }^{2}$ \\ Herly Carlos Teixeira Dias ${ }^{3}$ \\ ${ }^{1}$ Dona Gertrudes, nº 241, Centro - 36570-000 - Viçosa-MG, Brasil \\ diogolyra@gmail.com \\ 2Silvia Pontes, n51/apt. 202, Centro - 36570-000 - Viçosa-MG, Brasil \\ Diego.correa@ufv.br \\ ${ }^{3}$ Departamento de Engenharia Florestal/UFV, CEP 36570-000, Viçosa - MG, Brasil \\ herly@ufv.br
}

\begin{abstract}
This study was part of the restoration of riparian of River Gualaxo do Norte, in Monsenhor Horta, municipality of Mariana, MG, using native plants in the region. The survey is a follow-up of seedlings by two measurements, with six and eighteen months of age, is analyzing success rates and the increase in diameter of seedlings. Based on the results, it is recommended for the revegetation of degraded areas for the extraction of gold by dredging process, the species Anadenanthera macrocarpa (Angico-vermelho), Schinus terebinthifolius (Aroeira-pimenteira), Peltophorum dubiun (Canafístula), Senna spectabilis (Cássia-amendoin), Pseudobombax grandiflorum (Embiruçu), Schizolobium parahyba (Guapuruvu), Inga ssp (Ingá), Croton urucurana (Sangrad'água), Bixa orelana (Urucum).
\end{abstract}

Palavreas-chave: revegetation, gold mining, riparian, revegetação, garimpo de ouro, mata ciliar.

\section{INTRODUÇÃO}

A extração mineral é de grande importância para o desenvolvimento social, porém mostra-se responsável por impactos muitas vezes irreversíveis sobre o meio ambiente, Brandt (1998). O garimpo é uma atividade extrativista existente já há muito tempo no mundo. Os primeiros sinais dessa atividade datam do século XV, com os europeus que partiam em busca de novas terras para conquistar suas riquezas minerais. No Brasil, os garimpos começaram a despontar com maior destaque no século XVIII, com as campanhas em busca de ouro e diamantes no estado de Minas Gerais.

Dentre as atividades extrativistas, o garimpo talvez seja aquela que mais contribui para a degradação do meio ambiente, devido a técnicas rudimentares do processo tradicional, Edileuza et al.(1996). Tendo como uma de suas conseqüências a destruição da mata ciliar.

A mata ciliar funciona como filtro ambiental, retendo poluentes e sedimentos que chegariam aos cursos de água. Sua supressão pela garimpagem contribui para processos erosivos, lixiviação de nutrientes, assoreamento dos rios e afugentamento da fauna silvestre. A atividade envolve o revolvimento do solo, e seu rejeito é despejado diretamente nas águas do rio. Isto provoca a desconfiguração topográfica do terreno, havendo a formação de várias cavas secas ou inundadas. O despejo do rejeito no rio ocasiona a perda de argila, nutrientes e matéria orgânica por suspensão no curso d'água, que acarreta o aumento da turbidez e da quantidade de sólidos suspensos. Todos estes impactos deixam o solo paupérrimo, predominando em seu perfil apenas areia e cascalho.

Portanto, a manutenção dessa vegetação protege os recursos hídricos, conservando a qualidade, o volume das águas e o equilíbrio dos ecossistemas aquáticos. Além disso, contribui para a estabilização térmica de pequenos cursos de água através de interceptação e absorção da radiação solar pela copa de suas árvores.

Por todos esses motivos é considerada pela lei 4.771/65 do Código Florestal Federal como “Área de Preservação Permanente" por cumprir papel fundamental na proteção 
ambiental. Mesmo assim, essa vegetação não foi poupada da degradação no decorrer dos anos e as suas causas são as mais diversas: mineração, agropecuária, construção de hidrelétricas, poluição, estradas, dentre outros.

Frente a este panorama a recuperação de áreas degradadas assume um papel especial atuando de forma corretiva, a fim de conter processos da degradação.

Para a recuperação de áreas degradadas pela mineração, a revegetação é considerada parte essencial, não só pelo plantio de espécies, mas também pela seleção adequada destas, visando reconstituir e acelerar o processo de sucessão natural, Lourenzo (1991). A combinação de espécies de diferentes grupos ecológicos ou categorias sucessionais é favorável em um trecho degradado de mata ciliar, Ferreira e Dias (2004)

Modelos de recuperação de solos degradados se baseiam em tecnologias que promovam não apenas a utilização de espécies de crescimento rápido, mas que sejam capazes de melhorar o solo pelo aporte de matéria orgânica, melhoria esta que faz tanto pela deposição de material vegetal como pela reciclagem de nutrientes, Dias et al. (1994).

Além dos problemas ambientais, a atividade garimpeira sempre esteve atrelada a um ambiente muito hostil, muitos garimpos quase sempre estão associados a confrontos, assassinatos, roubos, disputas de terra, prostituição, vícios, insegurança, impunidade, patrocínio de armas e narcotráfico e à degradação ambiental. Isto porque os garimpos ilegais são extremamente difíceis de serem controlados, Peixoto et al. (2004).

Em busca de um maior controle deste meio, o governo introduziu significativa mudança na atividade garimpeira através da Lei $n .^{\circ} 7805 / 89$. Esse regime foi alterado com a instituição da permissão de lavra garimpeira, que descaracterizou o garimpeiro como trabalhador individual, favorecendo a formação de cooperativas. Estas têm como principal objetivo a sustentabilidade do sistema de produção, buscando a melhoria do aproveitamento das jazidas e melhores condições de vida aos garimpeiros, que têm nessa atividade uma importante alternativa de ocupação e sustento de suas famílias. Mesmo sendo uma grande oportunidade de melhorias para os garimpeiros, muitas cooperativas não funcionam da forma que deveriam, pois seus princípios básicos vão de encontro com valores culturais dos trabalhadores, onde se destaca a divisão do lucro entre todos seus componentes.

Em junho de 2008 foi sancionada a Lei Federal n. ${ }^{0}$ 1.685, que instituiu o Estatuto do Garimpeiro. Como preocupações centrais destacam-se a regulamentação da atividade garimpeira e a inclusão desse trabalho no rol das profissões reconhecidas pelo Estado.

Muitas vezes, as atividades garimpeiras acontecem de forma ilegal e após um período em operação, tais atividades são interrompidas pela exaustão das reservas, pelos altos custos da extração e, na maioria das vezes, pela ação dos órgãos ambientais, como no caso do garimpo do Engenho Velho - Monsenhor Horta, onde já ocorreram diversas autuações da Polícia Ambiental.

Para contornar essa situação, em 17/04/2004 foi criada a Cooperativa Regional Garimpeira de Mariana - COOPERGAMA, que atualmente busca encontrar solução legal (obtenção de Alvará de Lavra Garimpeira) e técnica para extração de ouro por draga no Rio Gualaxo do Norte em Monsenhor Horta, distrito de Mariana, MG.

Dentro do contexto acima, o presente trabalho tem como objetivo estudar e promover a recuperação do solo e a recomposição vegetal, prevista em lei, das áreas degradadas pela extração de ouro no Rio Gualaxo do Norte - Mariana, MG.

\section{MATERIAIS E MÉTODOS}

\section{1. Área de estudo}


A área experimental é o garimpo do Engenho Podre (Figura I), situa-se na região central do Estado de Minas Gerais, em um distrito de Mariana chamado Monsenhor Horta, situada dentro do bioma Mata Atlântica. As coordenadas geográficas aproximadas são de $20^{\circ} 14^{\prime} 21.34^{\prime \prime S}$ e $43^{\circ} 20^{\prime} 0.54$ ” O, com altitude de $607 \mathrm{~m}$. De acordo com a classificação Koppen o tipo climático da região é Cwa compreendendo um clima úmido com verão quente, estação seca curta e temperatura média anual entre $19,5-21,8^{\circ} \mathrm{C}$. Os meses de dezembro, janeiro e fevereiro são os que registram as maiores precipitações, sendo o índice médio pluviométrico anual de $1.800 \mathrm{~mm}$.

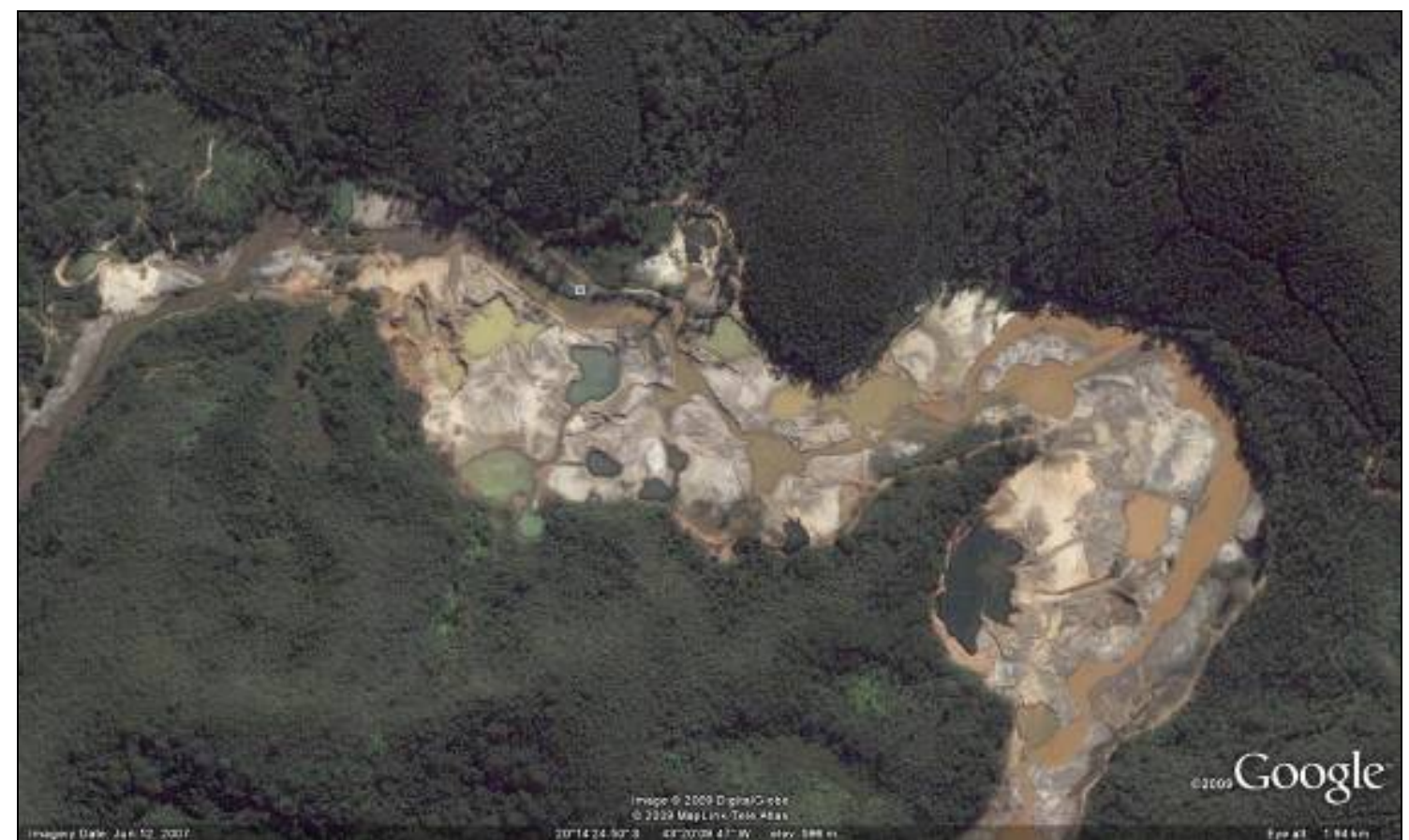

Figura I - Área de estudo do garimpo do Engenho Podre, no Rio Gualaxo do Norte, Mariana-MG, junho de 2007. Fonte: Google earth.

A economia de Monsenhor Horta baseia-se na atividade garimpeira nas margens do rio Galaxo do Norte. A atividade garimpeira na região existe desde a chegada dos Bandeirantes, há mais de 300 anos, e mais intensamente entre 1700 e 1750. Pode-se afirmar que, desde então, o garimpo tem demonstrado sustentabilidade enquanto atividade importante para a economia e cultura da região. Embora historicamente minimizador de pressão social, o garimpo, dado ao conjunto de práticas administrativas e ambientais inadequadas, está distante de atender aos princípios de desenvolvimento sustentável, Amade e Lima (2009).

A atividade garimpeira desordenada, em especial no município Monsenhor Horta, presencia um cenário assustador de degradação ambiental. Com o revolvimento do solo, devido ao processo de dragagem, não se encontra no local serrapilheira, e tão pouco banco de sementes, mesmo havendo fonte de propágulos na proximidade, onde se encontra uma mata nativa bem desenvolvida. Essa floresta sofreu pressão antrópica, pois o ouro está presente nas camadas mais profundas do terreno, às margens do rio e, muitas vezes no fundo do curso d’água. O processo de retirada do solo utilizando dragas, lançando o rejeito das calhas diretamente no leito do rio, provocou a desconfiguração topográfica do terreno, formação de grandes cavas secas ou inundadas, aumento da turbidez e da quantidade de sólidos suspensos na água, perda de argila e matéria orgânica do solo, predominando apenas areia e cascalho.

Diversas vezes o curso natural das águas foi modificado para a extração do mineral do fundo do rio. Com o aumento de precipitações mais intensas em épocas chuvosas, a força e a 
altura da lâmina d'água aumentam, ocasionando em enchentes, e forçando o rio a tomar seu caminho natural, o que gera desabamento do solo e mais impactos.

\subsection{Atividades desenvolvidas}

\subsubsection{Reconhecimento da área:}

As primeiras atividades desenvolvidas, no final do ano de 2006, foi uma conversa inicial com os membros da Cooperativa dos Garimpeiros de Mariana (COOPERGAMA), na qual eles nos apresentaram toda a área em exploração, as possíveis áreas para recuperação e uma única área onde as atividades de extração já haviam se encerrado.

\subsubsection{Nivelamento do terreno:}

No mês de novembro de 2007 foi realizada a terraplanagem do solo, utilizando-se um trator de pneu, com a finalidade de se recuperar as características de nível naturais do terreno.

\subsubsection{Plantio de mudas:}

Nos meses de janeiro e fevereiro de 2008 foram plantadas aproximadamente 4600. Nesta prática foram utilizadas apenas mudas nativas da região. A escolha das espécies foi feita com base em consultas à literatura, onde foram escolhidas mudas nativas da região que melhor se adaptam àquele clima e que são naturais de matas ciliares, pois devem se adaptar a ambientes propícios a encharcamentos e inundações.

O plantio das mudas foi realizado em linhas, onde se utilizou o modelo de quincôncio. Desta forma, foram utilizadas mudas de espécies pioneiras (P) e não-pioneiras (NP), plantadas alternadamente, sendo uma linha somente de espécies $\mathrm{P}$, e outra linha com espécies de mudas alternando entre P e NP, onde cada muda de NP deve ficar entre quatro de P.

O espaçamento escolhido foi de $3 \times 3 \mathrm{~m}$, com covas de $30 \times 30 \times 30 \mathrm{~cm}$, o coveamento foi realizado utilizando-se enxadão, e o substrato utilizado dentro das covas foi uma mistura de terra:esterco curtido na proporção de 2:1 v:v.

Foram realizados também combates às formigas cortadeiras, utilizando-se isca-granulada. A isca foi colocada próxima aos olheiros de trabalho dos formigueiros de terra solta encontrados nas proximidades do local onde foi realizado o plantio. Foi realizado um combate inicial.

Foi utilizada uma quantidade média de $10 \mathrm{~g}$ isca $/ \mathrm{m}^{2}$ de terra solta por formigueiro.

\subsubsection{Adubação:}

A adubação de arranque foi realizada um mês após o plantio. Foi utilizado 100g/muda de fertilizante NPK 6-30-6, colocados em duas covetas ao lado da planta, com 50g/coveta.

\subsubsection{Georreferenciamento:}

Foi feito um georreferenciamento da área total degradada, da área plantada e da área ainda não plantada, utilizando-se um GPS.

\subsubsection{Acompanhamento:}

Para o acompanhamento do crescimento e a medição da taxa de pegamento foram lançadas nove parcelas aleatórias, com dimensões de 10x20m. Realizou-se duas medições, a primeira seis meses após o plantio, em agosto 2008, e a segunda no mês de agosto de 2009. As mudas que estavam dentro das parcelas foram catalogadas, e foi realizada a medição de suas alturas e diâmetros. Para a medição da altura foi utilizada uma régua de madeira 
graduada, e mediu-se a altura da base da muda até sua última folha. Para a medição do diâmetro, foi adotado aquele referente ao caule no nível do solo, e como instrumento medidor utilizou-se um paquímetro digital.

Foi feito análise de pegamento e mortalidade das mudas utilizando-se o número inicial de mudas em cada parcela, e a quantidade de exemplares restantes nas duas medições.

Para análise de incremento em diâmetro foram utilizadas as espécies que melhor se adaptaram à área do plantio. Foi feito a diferença entre os diâmetros das mudas sobreviventes entre as duas medições. Estes dados foram avaliados através de estatística descritiva e teste de hipóteses para comparação de médias, utilizando-se teste-t com 5\% de significância.

\section{RESULTADOS E DISCUSSÃO}

Nos meses de janeiro e fevereiro foram plantadas aproximadamente 4600 mudas, sendo estas representadas por 24 espécies arbóreas diferentes (Tabela I). O plantio total abrangeu uma área aproximada de 4,1ha, medidos com GPS. Durante o mês de março duas precipitações provocaram fortes enchentes no local, ocasionando diversos problemas. O curso do rio se modificou, passando para uma área que havia sido plantada, em alguns locais houve desbarrancamento do terreno e diversas mudas foram soterradas e arrancadas em áreas onde houve alagamento.

Tabela I - Espécies plantadas para a revegetação do garimpo do Engenho Podre, às margens do Rio Gualaxo do Norte, Mariana-MG.

\begin{tabular}{|c|c|c|c|}
\hline Nome científico & Nome vulgar & Quantidade & $\begin{array}{l}\text { Grupo } \\
\text { ecológico }\end{array}$ \\
\hline Açoita-cavalo & Luehea grandiflora & 106 & $\mathrm{P}$ \\
\hline Angico-vermelho & Anadenanthera macrocarpa & 211 & $\mathrm{P}$ \\
\hline Aroeira-pimenteira & Schinus terebinthifolius & 276 & $\mathrm{P}$ \\
\hline Aroeira-brava & Lithraea molleoides & 157 & $\mathrm{P}$ \\
\hline Canafístula & Peltophorum dubiun & 105 & $\mathrm{P}$ \\
\hline Canelinha & Aniba firmula & 154 & $\mathrm{NP}$ \\
\hline Canjerana & Cabralea canjerana & 156 & $\mathrm{NP}$ \\
\hline Cássia-amendoin & Senna spectabilis & 109 & $\mathrm{P}$ \\
\hline Embaúba & Cecropia hololeuca & 146 & $\mathrm{P}$ \\
\hline Embiruçu & Pseudobombax grandiflorum & 105 & $\mathrm{P}$ \\
\hline Genipapo & Genipa americana & 104 & $\mathrm{P}$ \\
\hline Guapuruvu & Schizolobium parahyba & 104 & $\mathrm{P}$ \\
\hline Ingá & Inga ssp. & 1167 & $\mathrm{P}$ \\
\hline Ipê-amarelo & Tabebuia serratifolia & 105 & $\mathrm{NP}$ \\
\hline Ipê-branco & Tabebuia roseo alba & 106 & $\mathrm{NP}$ \\
\hline Ipê-rosa & Tabebuia spp. & 103 & $\mathrm{NP}$ \\
\hline Ipê-roxo & Tabebuia avellanedae & 208 & $\mathrm{NP}$ \\
\hline Não reconhecida & Não reconhecida & 103 & - \\
\hline Palmito Jussara & Euterpe edulis & 110 & $\mathrm{NP}$ \\
\hline Pau-d'álho & Gallesia integrifolia & 95 & $\mathrm{P}$ \\
\hline Pau-viola & Cytharexyllum myrianthum & 364 & $\mathrm{NP}$ \\
\hline Pitumba & Casearia pitumba & 104 & $\mathrm{NP}$ \\
\hline Sangra-d'água & Croton urucurana & 166 & $\mathrm{P}$ \\
\hline Sibipiruna & Caesalpinia peltophoroides & 105 & $\mathrm{P}$ \\
\hline Urucum & Bixa orelana & 108 & $\mathrm{P}$ \\
\hline
\end{tabular}


Estes acontecimentos danificaram grande parte do plantio, e com uma nova medição, também se utilizando GPS, constatou-se que a área plantada se reduziu a 2,7ha. Estima-se que 2970 mudas continuam plantadas no local.

Sucessivos ataques de formigas cortadeiras às mudas ocasionaram perdas as plantas. Nos primeiros meses após o plantio poucos ataques foram detectados, porém ao passar do tempo diagnosticou-se maiores danos às mudas.

Foi observada na área garimpada a emergência de plantas arbustivas. Tais espécies têm importância muito grande no aumento de matéria orgânica no solo, proteção e melhoria de tal. Estas plantas emergentes crescem em pequenas ilhas, e durante as visitas percebeu-se uma pequena dispersão destas, porém nada que comprometeu o crescimento das mudas plantadas. Faz-se necessário o acompanhamento destas plantas, tomando o cuidado adequado para que não se tornem uma praga no local, interferindo na recuperação da área pelas espécies arbóreas. Caso estas plantas tornem-se um empecilho para a revegetação, medidas mitigadoras devem ser adotadas para controlá-las.

Seis meses após o plantio foi constatado que 90,86\% das mudas sobreviveram e 9,14\% morreram. Aos 18 meses constatou-se que 73,4\% das mudas sobreviveram e 26,6\% não resistiram às condições precárias do solo, ao clima e aos sucessivos ataques de formigas. Dentre as mudas plantadas as espécies Schinus terebinthifolius, Senna spectabilis, Peltophorum dubiun, Inga ssp., Schizolobium parahyba e Pseudobombax grandiflorum obtiveram melhor pegamento, com porcentagens de 100\%, 100\%, 100\%, 90,9\%, 85,7\% e $75,0 \%$ respectivamente.

Tais espécies apresentaram alta taxa de pegamento, pois, alem de enquadrarem-se no grupo ecológico das pioneiras, apresentaram grande capacidade de brotação após ataques de formigas e se adaptaram muito bem às condições do solo degradado pela mineração.

Em contrapartida, as espécies, Cabralea canjerana, Aniba firmula e Euterpe edulis tiveram taxas de pegamento muito baixas, com valores de 40,0\%, 33,3\% e 0,0\% respectivamente.

Como estas espécies se tratam de plantas não-pioneiras, a quantidade de radiação solar e as condições intrínsecas do local foram fatores determinantes nas baixas taxas de pegamento apresentadas por estas.

Utilizando os dados da primeira e segunda medição, obtivemos o incremento médio em diâmetro das espécies. Analisando as nove espécies que apresentaram melhor adaptação ao local (Tabela II), a Aroeira-pimenteira, o Genipapo e o Ingá foram aquelas que apresentaram o menor valor, não diferindo entre si $(\mathrm{p}>0,05)$. A espécie que apresentou melhor incremento foi o Embiruçu, sendo esta diferente significamente das três espécies acima. Esta diferença de diâmetro é devido a sua morfologia, pois apresenta um abaulamento na base do caule. Os demais exemplares apresentaram valores de incremento médio de diâmetro intermediário.

Tabela II - média do incremento em diâmetro dos seis aos 18 meses das espécies mais adaptadas; médias com mesmas letras minúsculas em cada coluna não diferem entre si pelo teste de $\mathrm{t}(\mathrm{p}>0,05)$.

\begin{tabular}{|c|c|}
\hline Espécie & Média do Incremento do diâmetro (cm) \\
\hline Canafístula Total & $0,799750 \mathrm{a}$ \\
\hline Sangra-d'água & $0,846500 \mathrm{a}$ \\
\hline Ingá & $0,932574 \mathrm{a}$ \\
\hline Guapuruvu & $1,206750 \mathrm{ab}$ \\
\hline Aroeira-pimenteira & $1,464875 \mathrm{ab}$ \\
\hline Cássia-amendoin & $1,605750 \mathrm{ab}$ \\
\hline Angico-vermelho & $1,812000 \mathrm{ab}$ \\
\hline Urucum & $1,838667 \mathrm{ab}$ \\
\hline Embiruçu & $2,672975 \mathrm{~b}$ \\
\hline
\end{tabular}


Dezoito meses após o plantio podemos observar a modificação da área pela presença das plantas no local (Figura II).

(A)

(B)

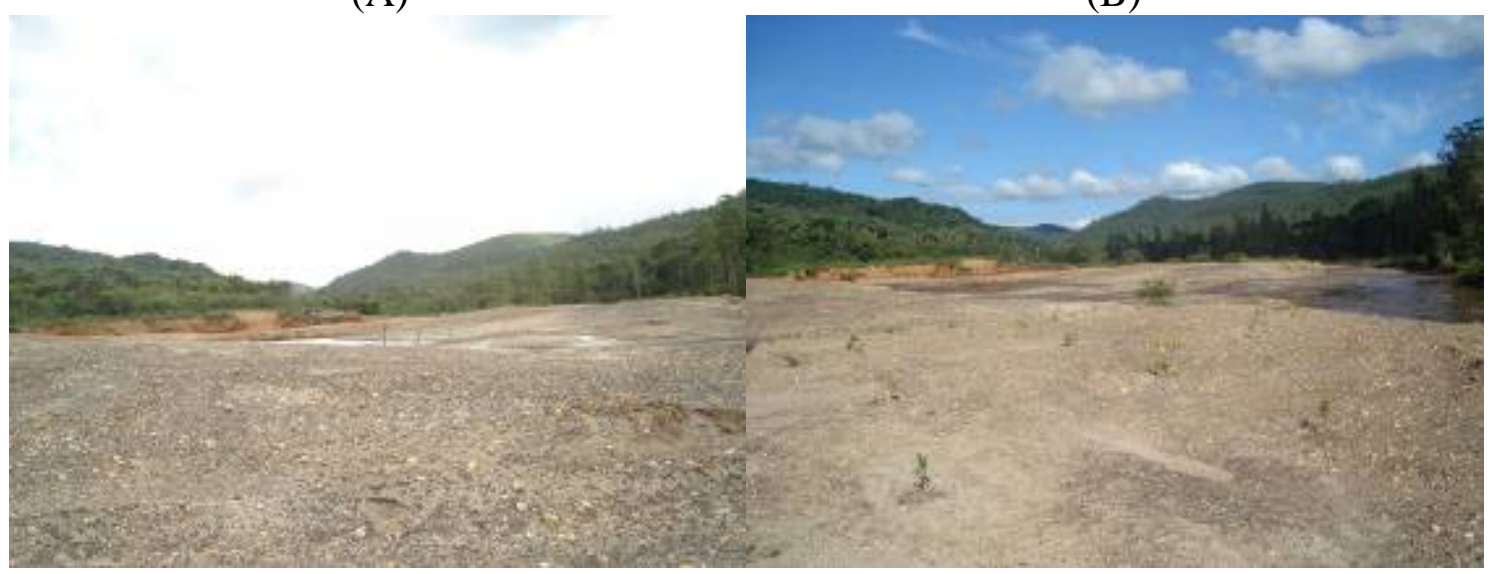

(C)

(D)

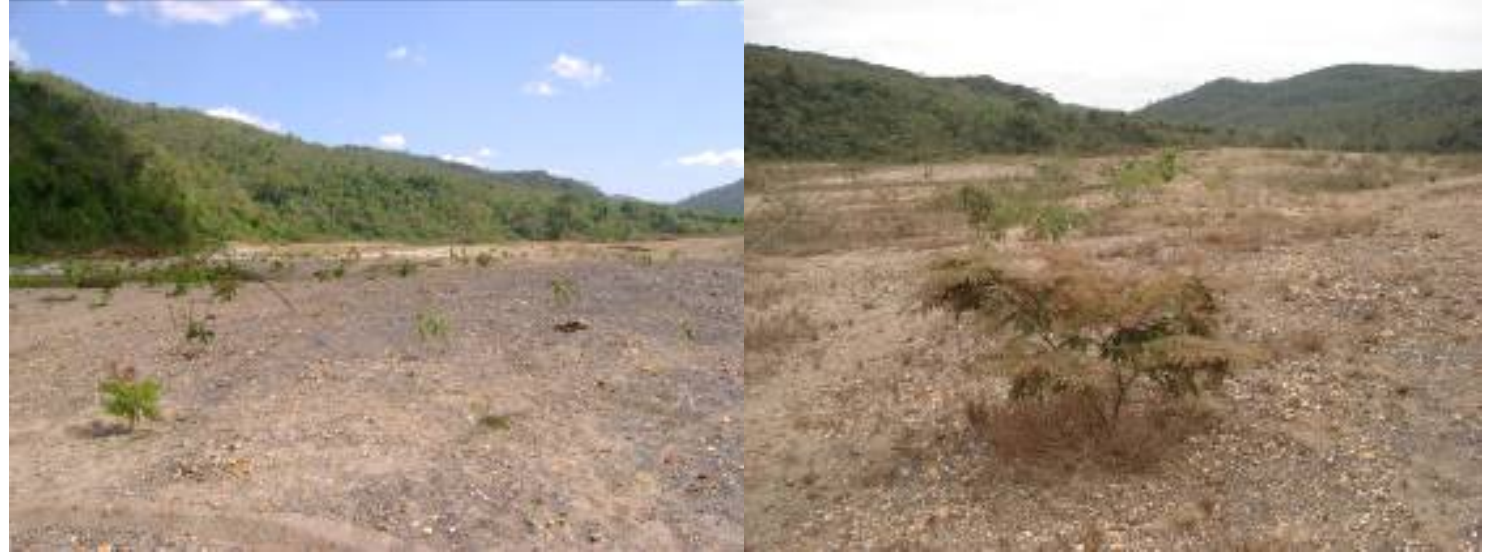

Figura II - Fotografia do garimpo antes do plantio, no dia 12/12/2007 (A); foto do garimpo logo após o plantio, no dia 14/02/2008 (B); imagem do garimpo na época da primeira medição das mudas, dia 15/08/2008 (C); e foto do garimpo na época da segunda medição das mudas, no dia 22/08/2009, às margens do Rio Gualaxo do Norte, Mariana-MG.

Não podemos esquecer que, possivelmente, estas plantas estariam com diâmetros maiores do que os atuais, caso não tivessem sofrido sucessivos ataques de formigas cortadeiras.

Devido estes eventos, a análise dos dados das alturas se tornou inviável, pois o incremento médio de diversas espécies apresentou-se negativos.

\section{CONCLUSÃO}

A atividade garimpeira trás sérios problemas ambientais quanto à qualidade dos cursos d’água, do solo e da vegetação ripária. A revegetação da área degradada utilizando-se mudas de espécies nativas, em conjunto de técnicas silviculturais adequadas, é de extrema importância para acelerar a recuperação do local.

Nas condições atuais do garimpo, 18 meses após o plantio, pode-se dizer de maneira preliminar que as espécies mais promissoras para a recuperação da área em relação ao incremento médio em diâmetro são: Pseudobombax grandiflorum (Embiruçu), Bixa orelana (Urucum), Anadenanthera macrocarpa (Angico-vermelho) e Senna spectabilis (Cássia-amendoin); quanto a taxa de pegamento, são: Schinus terebinthifolius (Aroeira-pimenteira), Senna spectabilis (Cássia-amendoin), Peltophorum dubiun (Canafístula), Inga ssp. (Ingá), Schizolobium parahyba (Guapuruvu) e Pseudobombax grandiflorum (Embiruçu). 
Recomenda-se, para a revegetação de áreas degradadas pela atividade de extração de ouro utilizando-se draga, as espécies: Anadenanthera macrocarpa (Angico-vermelho), Schinus terebinthifolius (Aroeira-pimenteira), Peltophorum dubiun (Canafístula), Senna spectabilis (Cássia-amendoin), Pseudobombax grandiflorum (Embiruçu), Schizolobium parahyba (Guapuruvu), Inga ssp (Ingá), Croton urucurana (Sangra-d'água), Bixa orelana (Urucum).

\section{AGRADECIMENTO}

Os autores agradecem à FAPEMIG pelo incentivo financeiro, e aos colaboradores pelo apoio neste trabalho.

\section{REVISÃO BIBLIOGRÁFICA}

AMADE, P., LIMA, H. M. Desenvolvimento sustentável e garimpo - o caso do Garimpo do Engenho Podre em Mariana, Minas Gerais. Revista Escola de Minas, vol.62, nº.2, Ouro Preto, abril/junho, 2009, p. 237-242.

BRANDT, W. Avaliação de cenários em planos de fechamento de minas. DIAS, L. E.; MELLO, J. W. V. (Ed.) Recuperação de áreas degradadas. Viçosa: UFV/Departamento de Solos/Sociedade Brasileira de Recuperação de Áreas Degradadas, 1998. p. 131-134.

DIAS, L.E e MELLO, J.W.V. (Editores) Recuperação de Áreas Degradadas. Editora Folha de Viçosa Ltda. Viçosa, 1998. 251p.

FERREIRA, D. A. C.; DIAS, H. C. T. Situação atual da mata ciliar do Ribeirão São Bartolomeu em Viçosa, MG. Revista Árvore, Viçosa-MG, v.28, n.4, p.617-623, 2004.

LOURENZO, J. S. Regeneração natural de uma área minerada de bauxita em Poços de Caldas, Minas Gerais. 1991. 151 p. Dissertação (Mestrado em Ciências Florestal) - Universidade Federal de Viçosa, Viçosa, MG.

MELO, E. C., ALMEIDA FILHO, R. Mapeamento de Áreas Degradadas Pela Atividade de Garimpos na Região da Serra Tepequém (RR), Através de Imagens Landsat-TM. Anais VIII Simpósio Brasileiro de Sensoriamento Remoto, Salvador, Brasil, 14-19 abril, 1996, INPE, p. 639-645.

PEIXOTO R.J., LIMA, H. M. Diagnóstico dos garimpos de topázio imperial no Alto Maracujá, Sub-bacia do rio das Velhas, MG. Revista Escola de Minas vol.57, nº.4, Ouro Preto, Oct./Dec. 2004. 